\title{
A rapid method for electron microscopic examination of blood cells
}

\author{
ANTONIO COPPOLA \\ From the Department of Pathology, College of Medicine, Downstate Medical Center, State University of \\ New York, Brooklyn, NY 11203, USA
}

SUMMARY A method is described whereby the time required for the processing of white blood cells for electron microscopy can be shortened from 36 to $3 \frac{1}{2}$ hours. Because cells of the peripheral blood are not attached to each other, fixation, dehydration, and infiltration of the embedding medium is more rapid. This makes it possible for clinicians to use fine structural data for diagnosis as illustrated in three cases.

In haematology little emphasis has been placed on electron microscopy for diagnostic purposes. One of the principal reasons may be that with standard methods for electron microscopy the time required for the fixation and embedding of the specimens is approximately 36 hours (Bessis, 1973). In haematology the electron microscope has therefore been considered primarily a tool for research purposes.

It has been proposed, however, that in the study of the bone marrow, in addition to smears, sections of particles, bone biopsy, and cytochemistry, fine structural study should also be done if light microscopic methods fail to reveal the nature of the cells or if it is necessary to define cells ultrastructurally (Coppola and Athanassiades, 1977). However, the accepted procedures require 24-48 hours for regular processing for electron microscopy. So it is convenient to have a rapid method for fine structural analysis of cells.

It is the purpose of this paper to present evidence that haemopoietic cells can be processed for electron microscopy and examined in $3 \frac{1}{2}$ hours. The clinician will thus have quick access to fine structural data which will aid in making the exact diagnosis in difficult haematological cases.

\section{Material and methods}

Electron microscopic examination of peripheral blood taken from patients with leukaemias was done by both the quick method of fixation and embedding and the standard method.

Received for publication 19 July 1978
Two 5-ml aliquots of peripheral blood from each patient were placed into test tubes containing EDTA. The blood was kept for 30 minutes in the vertical position at $4^{\circ} \mathrm{C}$. The plasma layers rich in white blood cells (WBC) were then aspirated, placed into other test tubes, and centrifuged at $2000 \mathrm{rpm}$ for 10 minutes in a Clay-Adams centrifuge. The plasma supernatants were discarded from each tube, and the two pellets from each patient were labelled for either the rapid experimental procedure or the control procedure. They were then processed as described below.

\section{Experimental procedure}

The cells were immediately resuspended in sodiumcacodylate buffered glutaraldehyde, $\mathrm{pH} 7 \cdot 4$ (Sabatini et al., 1963) and kept for 10 minutes at $4^{\circ} \mathrm{C}$. After the primary aldehyde fixation, they were washed three times in sodium cacodylate buffer over six minutes, and then postosmicated in sodium-acetate-sodiumveronal-buffered osmium tetroxide, $\mathrm{pH} 7 \cdot 4$ (Palade, 1952) for 15 minutes. The cells were subsequently washed for three minutes in $35 \%, 50 \%, 70 \%$, and $95 \%$ alcohol. The dehydration was further accomplished by two washes in absolute alcohol and two changes in propylene oxide washes over six minutes. After this last step the cells were suspended in a propylene-Epon mixture for 10 minutes, and then placed into Beam capsules and centrifuged at 3000 rpm for five minutes. The propylene-Epon mixture was then aspirated, and Epon was introduced into the capsules (Luft, 1961). The Beam capsules containing packed cells at the tip were kept at $37^{\circ} \mathrm{C}$ for 
45 minutes, and subsequently Epon polymerisation was carried out at $100^{\circ} \mathrm{C}$ for one hour. After cooling, the blocks were cut with glass and diamond knives. Thick sections were stained with toluidine blue (Trump et al., 1961) and thin sections with methanolic uranyl acetate (Stempak and Ward, 1964).

CONTROL PROCEDURE

WBC from the same patients were processed according to our routine method over a 24-hour period (Bessis, 1973; Coppola, 1973). In summary, the cell pellets were cut into blocks less than $1 \mathrm{~mm}^{3}$, fixed for one hour in buffered glutaraldehyde, and postfixed in osmium tetroxide for an additional hour. Subsequently, the cell pellets were dehydrated in graded alcohols and propylene oxide over $2 \frac{1}{2}$ hours. Finally, the cell pellets were embedded in Epon 812 and polymerisation was performed at $60^{\circ} \mathrm{C}$ for 17-18 hours.

\section{Results}

Complete polymerisation of the Epon blocks was obtained within one hour at $100^{\circ} \mathrm{C}$. Thick sections were easily cut and were well stained with toluidine blue. No difficulties were encountered in cutting thin sections with a diamond knife. When the thin sections were cut, stained with uranyl acetate, and examined with the electron microscope we could see little difference between the rapid and the conventional methods. There was a slight decrease in the cytoplasmic translucency and the cytoplasm often appeared of increased density in the rapidly processed material. Cytoplasmic granules were darker and somewhat better defined in the conventionally fixed cells. However, with the rapid method there was very good preservation of both organelles and granules. The morphology of the granules was adequate for identification of cell types and their stage of maturation. Three illustrative cases follow.

\section{PATIENT 1}

A 34-year-old woman with a two-year history of chronic myeloid leukaemia was admitted to hospital. While the patient was still in the emergency room, examination of the peripheral blood revealed a WBC of $79 \times 10^{9} / 1$. The smear showed a total spectrum of granulocyte maturity, which was compatible with the diagnosis of chronic granulocytic leukaemia, but there were also $24 \%$ blast cells that were peroxidasenegative. The peripheral blood was prepared for electron microscopy in order better to define the nature of the blast cells. Ultrastructurally, these blast cells appeared to have an agranular cytoplasm, displaying the general appearance of lymphoblasts (Fig. 1). The occurrence of lymphoid cells in the blastic crisis of chronic granulocytic leukaemia has recently been stressed (Rosenthal et al., 1977). The structure of the other leukaemic cells was not unusual: their granules, mitochondria, Golgi apparatus, ribosomes, plasma membranes, nuclear envelopes, chromatin, and nucleoli were similar to those usually seen in such cases (Figs 2, 3, 4). The diagnosis of chronic granulocytic leukaemia in blastic crisis was confirmed.

\section{PATIENT 2}

A 64-year-old woman was admitted with purple macular lesions on the chest. In the emergency room her WBC was $10.5 \times 10^{9} / 1$. The differential count showed $39 \%$ monocytoid cells, some of which were immature. The peripheral blood was then studied by electron microscopy. Ultrastructurally, mature and immature monocytoid cells were seen (Fig. 5). These were characterised by kidney-shaped or irregularly shaped nuclei, which contained a variable amount of chromatin which rarely was seen attached and condensed against the nuclear envelope. Approximately $5 \%$ of them were markedly convoluted. The cytoplasm contained the usual organelles as seen in monocytes. Some cells displayed a variable number of pleomorphic granules and vacuoles. Also in this case on high power magnification there was an excellent resolution of the cytoplasmic organelles (Fig. 6). The diagnosis of acute monocytic leukaemia was made from this material, substantiating the diagnosis made on the light microscopic characters of the cells in the petipheral blood.

\section{PATIENT 3}

A 67-year-old man was admitted to hospital with progressive pruritic dermatitis of four years' duration. The WBC in the emergency room was $120 \times 10^{9} / 1$. Sezary's syndrome was suspected because $30 \%$ of lymphocytes had cerebriform, convoluted nuclei and cytoplasmic vacuoles. Ultrastructurally, the cells of this patient had the characteristic features of Sezary's cells, that is, cerebriform-shaped nuclei with condensed chromatin adjacent to the nuclear envelope. Occasionally large nucleoli were seen (Figs 7 and 8). Thus we were able to provide the clinician with accurate diagnostic data in a very short period of time.

\section{Discussion}

Fixatives and embedding media for electron microscopy have been greatly improved over the past 20 years. In our experience, glutaraldehyde-osmium fixation gives the best cellular detail. The best embedding medium is the epoxy resin suggested by Luft (1961). The suggested time for fixation and 


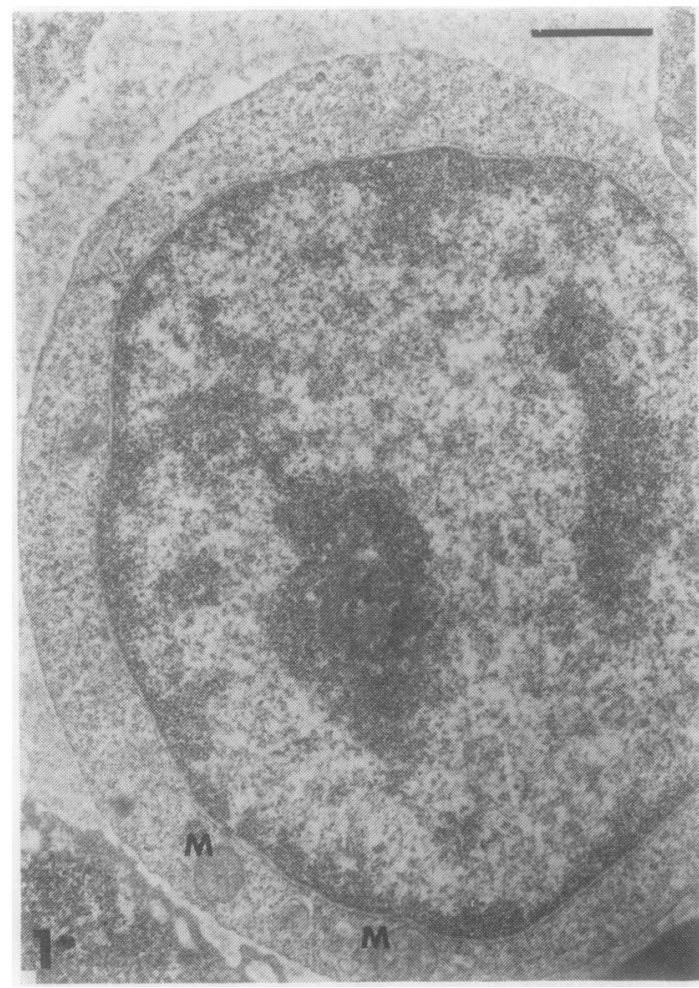

Fig. 1 An agranular malignant cell with morphological characteristics of a lymphoblast. $M=$ mitochondria. Uranyl acetate $\times 12054$.

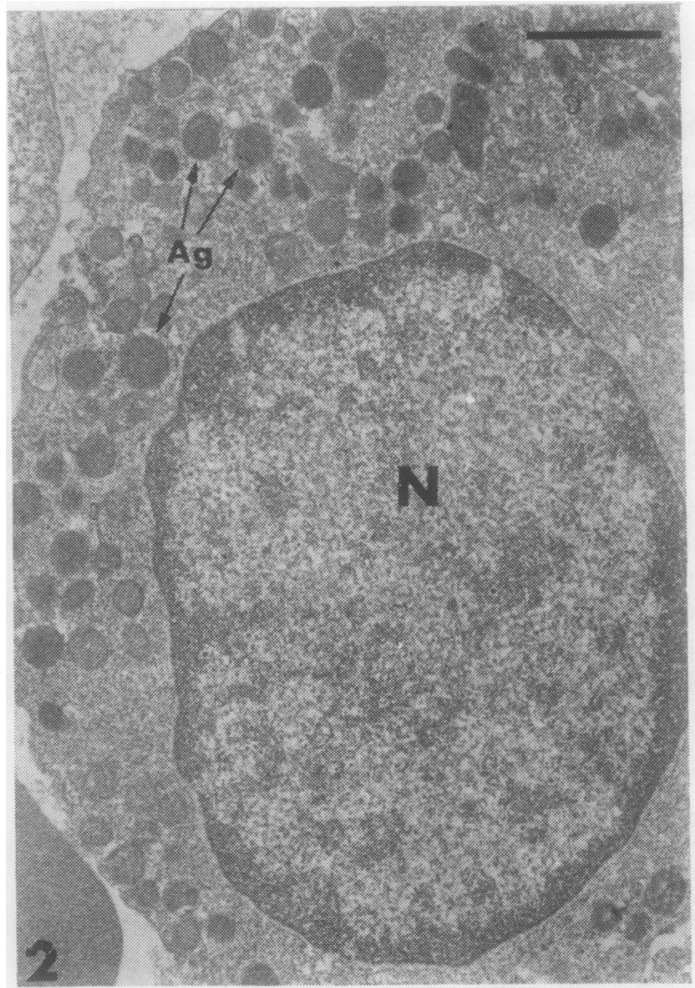

Fig. 2 A myelocyte displaying normal cytoplasmic granules and nuclear chromatin. Ag = azurophilic granules; $N=$ nucleus. Uranyl acetate $\times 13560$.

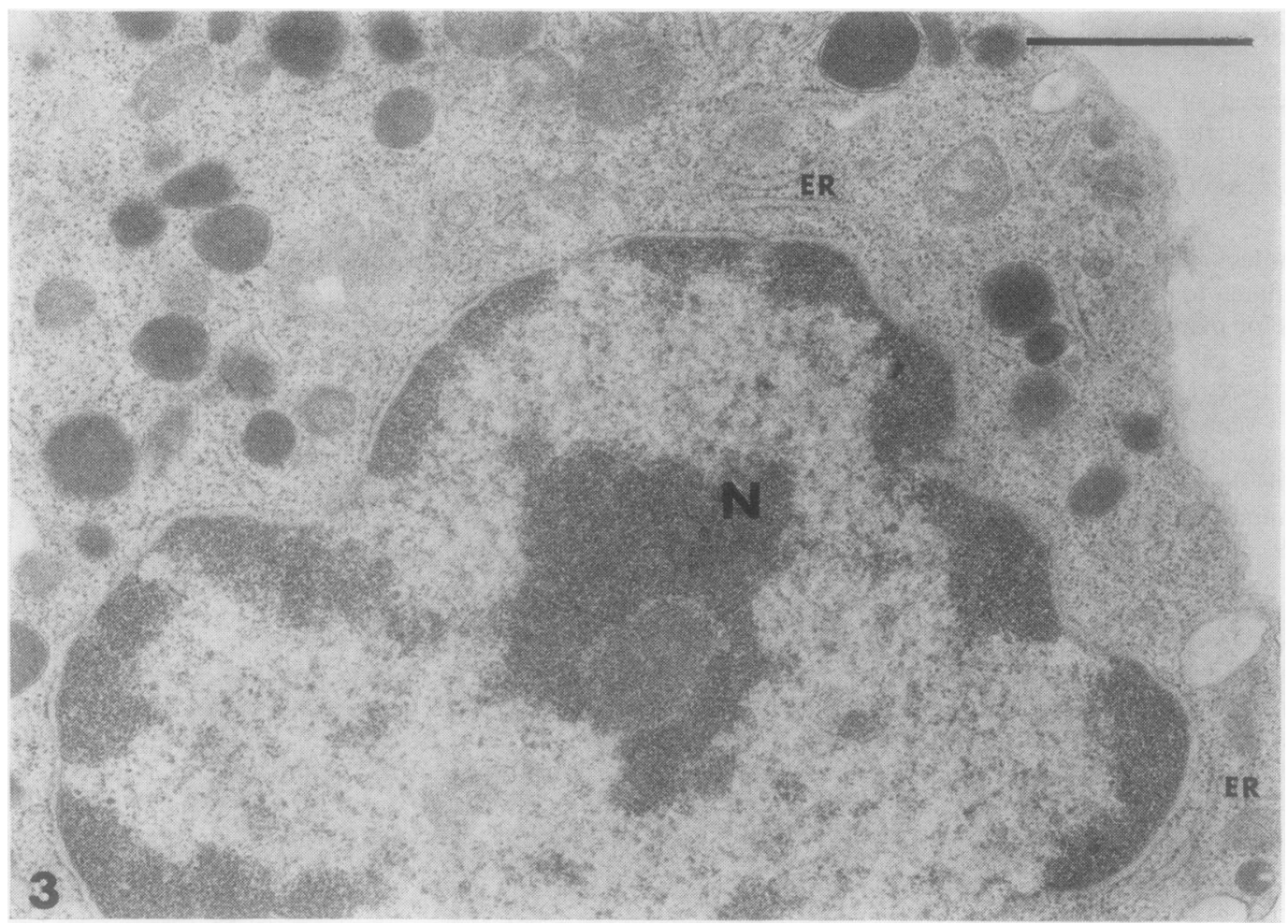

Fig. 3 Note excellent preservation of the nucleus, nucleolus, and cytoplasmic organelles of this leukaemic myelocyte. $E R=$ rough endoplasmic reticulum; $N=$ nucleus. Uranyl acetate $\times 23985$. 


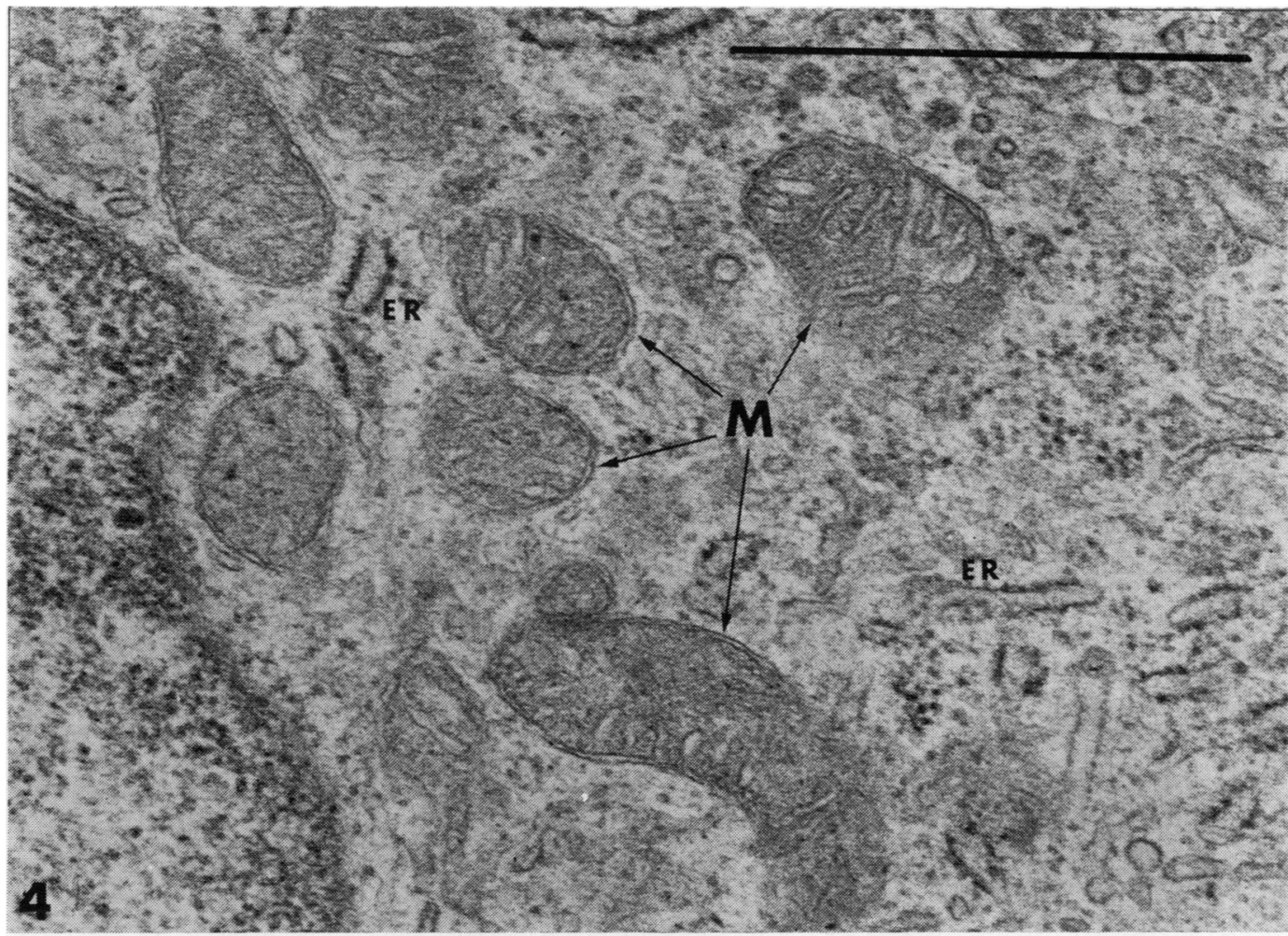

Fig. 4 The structure of the mitochondria and profiles of the rough endoplasmic reticulum are clearly delineated in this myeloid cell. $\dot{E} R=$ rough endoplasmic reticulum; $M=$ mitochondria. Uranyl acetate $\times 55965$.

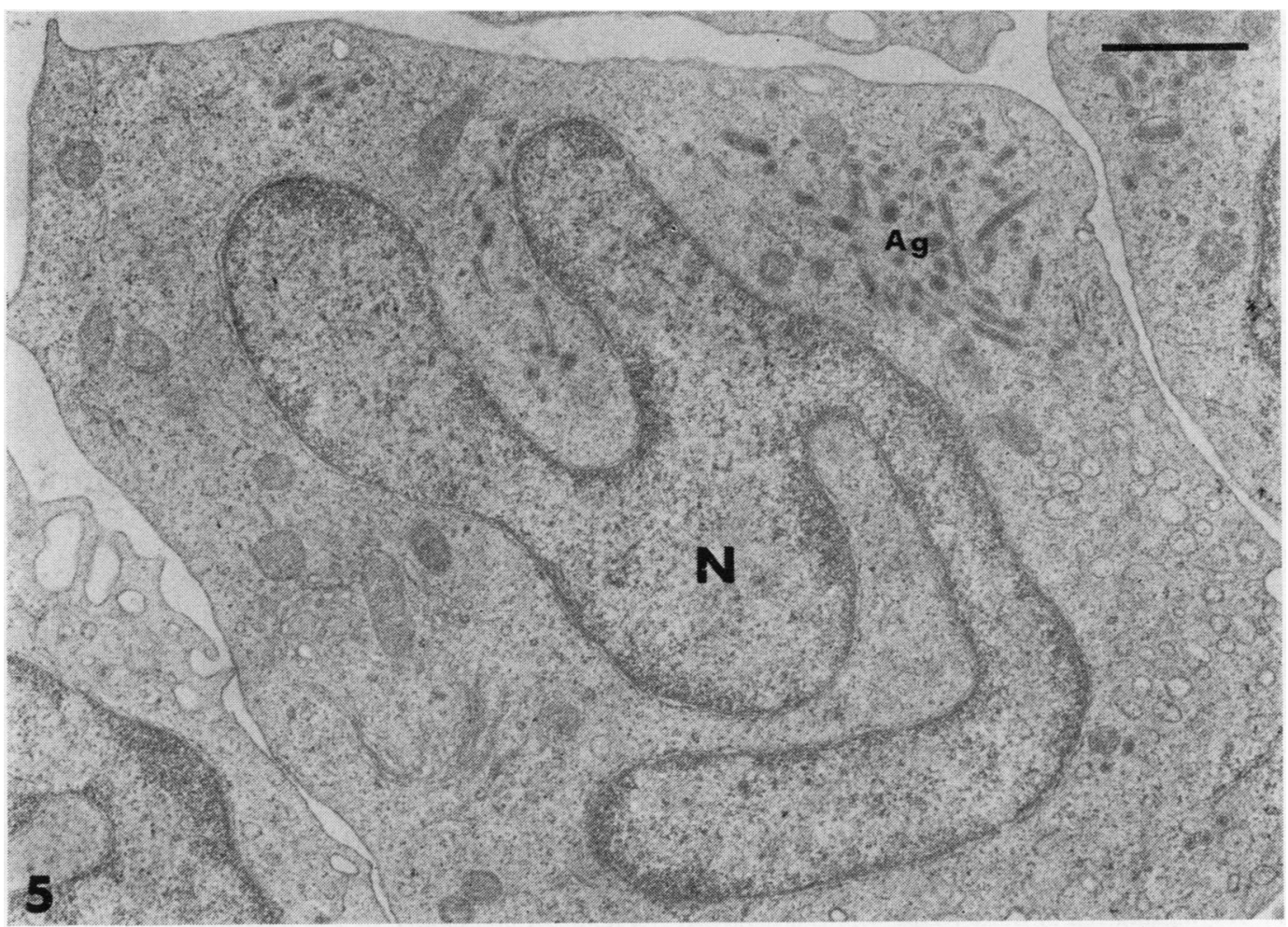

Fig. 5 A malignant monocyte showing a bizarre shape of the nucleus and abundance of azurophilic granules along with other cytoplasmic organelles. Ag = azurophilic granules; $N=$ nucleus. Uranyl acetate $\times 15590$, 


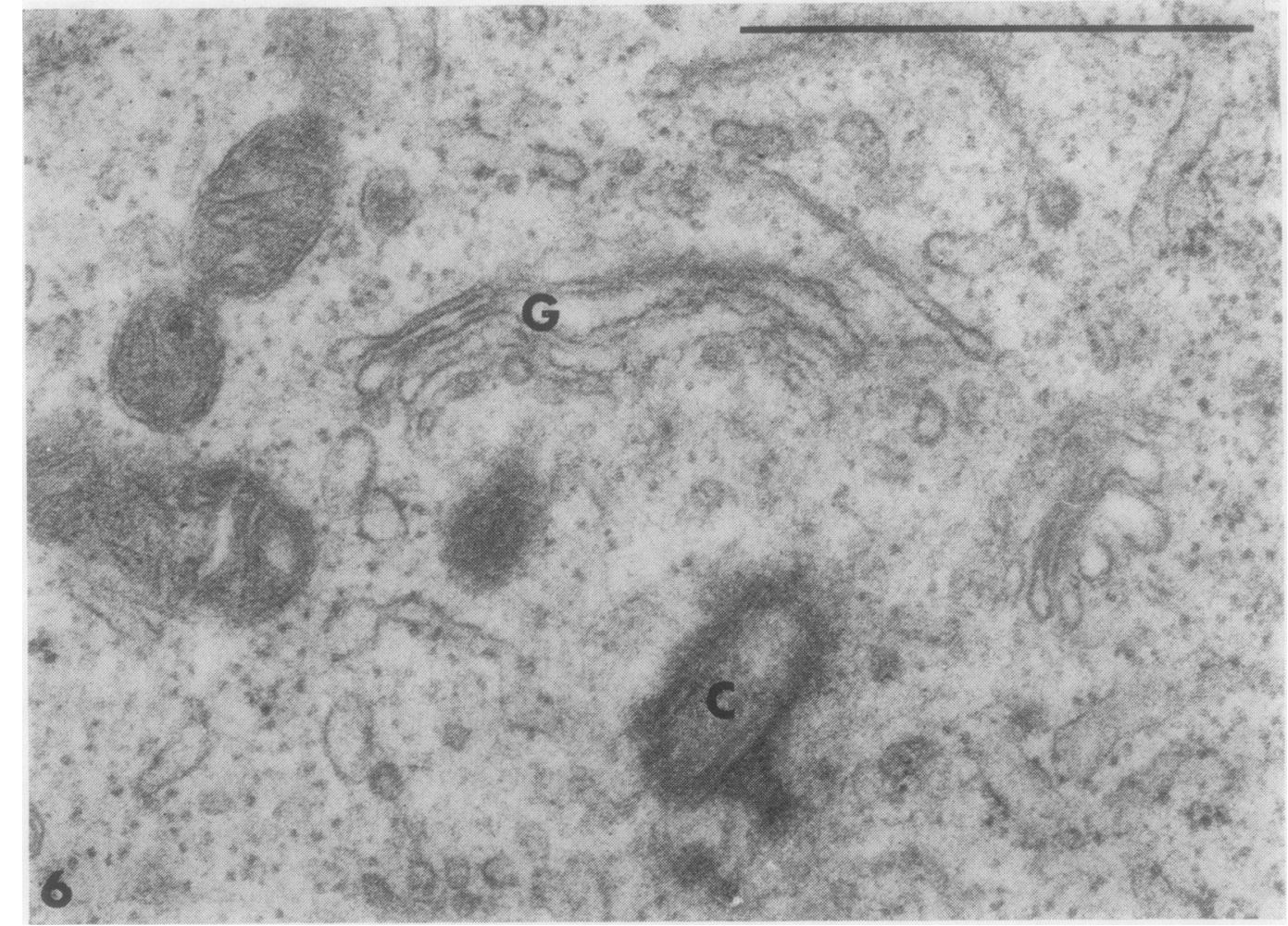

Fig. 6 At this magnification ribosomes, centriole, and membranous structures of the Golgi apparatus $(G)$ are clearly demonstrated. $C=$ centriole; Uranyl acetate $\times 55965$.

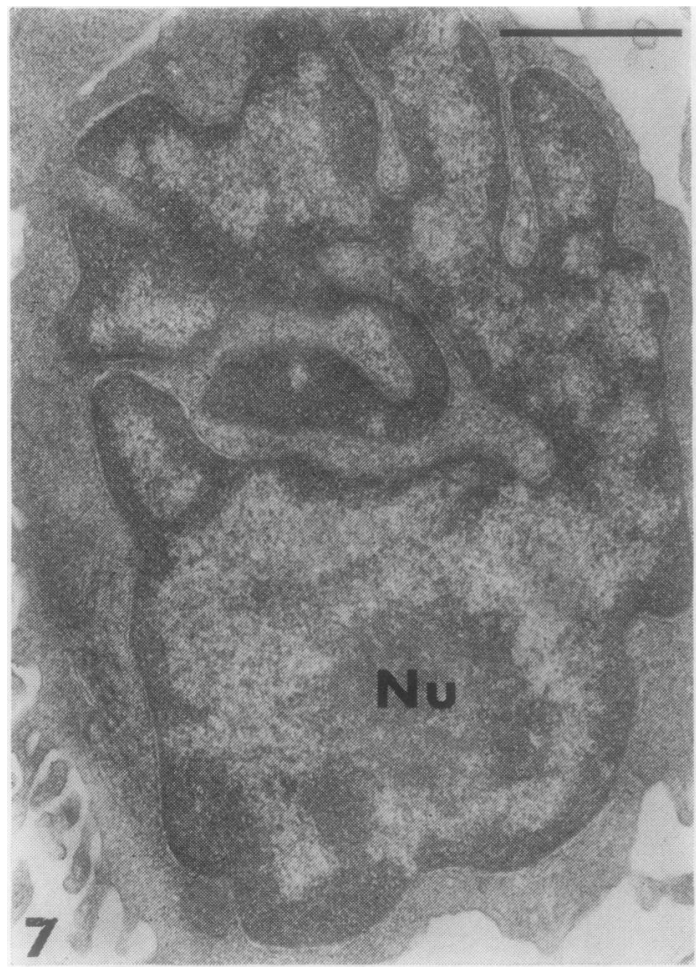

Fig. 7 A lymphoid cell of Sezary type with characteristic cerebriform-shaped nucleus. A large nucleolus is also seen. $\mathrm{Nu}=$ nucleolus. Uranyl acetate $\times 18282$.

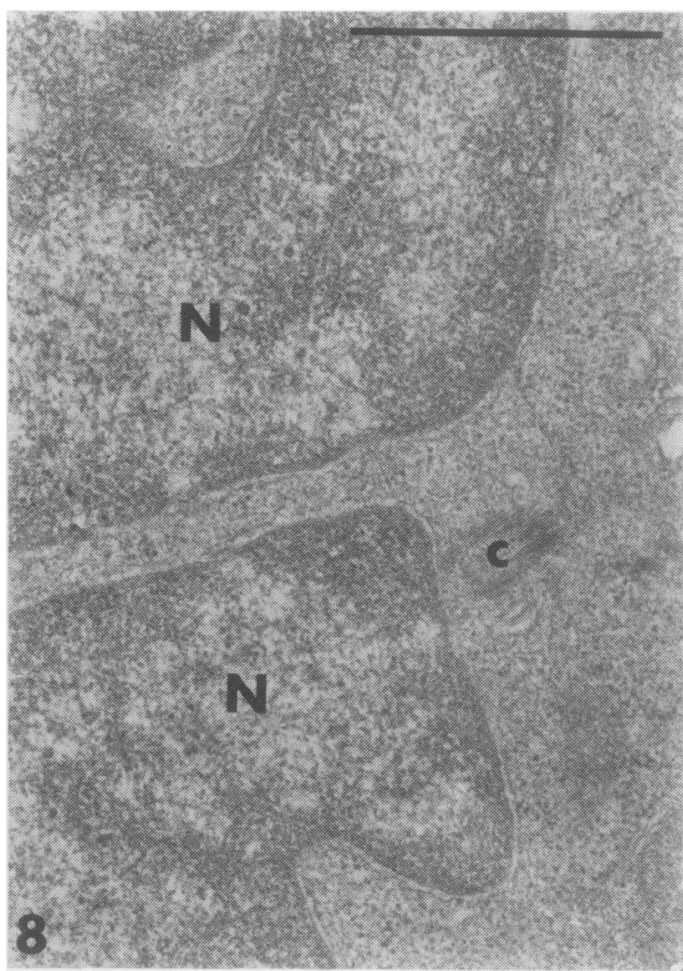

Fig. 8 A high-power view of a Sezary cell. $C=$ centriole; $N=$ nucleus. Uranyl acetate $\times 3121 !$ 
dehydration is approximately 7 hours and the time required for the Epon infiltration and polymerisation is about 24 hours (Bessis, 1973). With the present modified procedure, we have shown that the time required for the entire processing for electron microscopy can be shortened to $3 \frac{1}{2}$ hours provided that the temperature for the Epon polymerisation is raised to $100^{\circ} \mathrm{C}$. In our experience, using this method in many cases, no appreciable cell distortion nor artifacts have been noted. The only inconvenience is that, because of the centrifugation that follows every step, only one specimen can be processed at a time. We have therefore limited our procedure to those cases in which electron microscopy is of immediate diagnostic value.

An analogous method has already proved to be excellent for tissue biopsies (Rowden et al., 1974). Since we are dealing not with solid tissue but with buffy coat, the fixation, dehydration, and embedding steps can be rapidly achieved even when there is a large pellet. Despite the high temperature used for the polymerisation of the resin, there is no detectable cellular distortion nor shrinkage of cells (Rowden et al., 1974). We recommend the use of the rapid procedure so that the clinical haematologist may add evaluation of the fine structural detail to the other information he has available before making the final diagnosis.

I am indebted to Thomas J. Athanassiades and Dr Joanna Sher for their critical review of the manuscript. The technical assistance of Alan Lieberman and Nilda Stahl is also appreciated. The generous support of the project by $\mathrm{Dr}$ John D. Broome, Professor and Chairman, Department of Pathology, is also gratefully acknowledged.

\section{References}

Bessis, M. (1973). Living Blood Cells and their Ultrastructure, translated by R. I. Weed, p. 717. Springer, New York and Berlin.

Coppola, A. (1973). A transplantable mouse lymphoma with unusual azurophilic granules. American Journal of Pathology, 73, 233-239.

Coppola, A., and Athanassiades, T. J. (1977). The relative merits of bone marrow biopsy and particle section technics (Letter). American Journal of Clinical Pathology, 67, 309.

Luft, J. H. (1961). Improvements in epoxy resin embedding methods. Journal of Biophysical and Biochemical Cytology, 9, 409-414.

Palade, G. E. (1952). A study of fixation for electron microscopy. Journal of Experimental Medicine, 95, 285-298.

Rosenthal, S., Canellos, G. P., Whang-Peng, J., and Gralnick, H. R. (1977). Blast crisis of chronic granulocytic leukemia: morphologic variants and therapeutic implications. American Journal of Medicine, 63, 542-547.

Sabatini, D. D., Bensch, K.. and Barrnett, R. J. (1963). Cytochemistry and electron microscopy: the preservation of cellular ultrastructure and enzymatic activity by aldehyde fixation. Journal of Cell Biology, 17, 19-58.

Rowden, G., and Lewis, M. G. (1974). Experience with a three hour electron microscopy biopsy service. Journal of Clinical Pathology, 27, 505-510.

Stempak, J. G., and Ward, R. T. (1964). An improved staining method for electron microscopy. Journal of Cell Biology, 22, 697-701.

Trump, B. F., Smuckler, E. A., and Benditt, E. P. (1961). A method for staining epoxy sections for light microscopy. Journal of Ultrastructure Research, 5, 343-348.

Requests for reprints to: Dr Antonio Coppola, Department of Pathology, Downstate Medical Center, State University of New York, 450 Clarkson Avenue, Brooklyn, New York 11203, USA. 